\title{
SIN DIOS, REY NI LEY. EXCESOS, CRÍTICA Y REFORMA DE LA INQUISICIÓN EN LA DEFENSA DE MACANAZ A LA HISTORIA CIVIL DE ESPAÑA, DE BELANDO*
}

\author{
POR \\ FRANCISCO PRECIOSO IZQUIERDO ${ }^{1}$ \\ Universidad de Murcia
}

\section{RESUMEN}

A mediados de 1744 la Inquisición estrechaba el cerco sobre la Historia Civil de España, obra de fray Nicolás de Jesús Belando. La identificación del autor con las posiciones más regalistas encarnadas por el polémico ex fiscal general del Consejo de Castilla, Melchor Macanaz, y las críticas al tribunal por su proceder durante el bienio reformista de 1713-1715, rebasaba con creces lo tolerado por las autoridades del Santo Oficio. En este artículo profundizamos en la interpretación que mereció para Macanaz el proceso inquisitorial de Belando, una oportunidad que le permitió insistir en la idea de una Inquisición subordinada al rey y dependiente de su jurisdicción como medio único de adecuación de la institución al Estado real absoluto.

PALABRAS CLAVE: Melchor Macanaz; fray Nicolás Jesús Belando; España borbónica; Historia Civil de España; Inquisición.

\section{WITHOUT GOD, EITHER KING OR LAW. EXCESS, CRITICAL AND REFORM OF THE INQUISITION IN THE DEFENSE OF MACANAZ TO BELANDO'S HISTORIA CIVIL DE ESPAÑA}

\begin{abstract}
At the end of 1744 the Spanish Inquisition persecuted the work of the religious Nicholas de Jesus Belando, Historia Civil de España. The origin of the problem was the critic of the author to the action of the Inquisition against Melchor Macanaz. In this article we analyze the interpretation of Macanaz to the inquisitorial process of Belando, an opportunity that allowed him to insist on his personal and political vindication and in his worldview of an Inquisition subordinated to the king and dependent of its jurisdiction as means of adaptation of the institution to the absolute State.
\end{abstract}

KEY WORDS: Melchor Macanaz; fray Nicolás Jesús Belando; Bourbon Spain; Historia Civil de España; Inquisition.

Cómo CITAR ESTE ARTículo / CITATION: Precioso Izquierdo, Francisco. 2019. «Sin Dios, Rey ni Ley. Excesos, crítica y reforma de la Inquisición en la defensa de Macanaz a la Historia Civil de España, de Belando». Hispania Sacra 71, 144: 577-587. https://doi. org/10.3989/hs.2019.041

Recibido/Received 01-02-2017

Aceptado/Accepted 20-02-2018

\footnotetext{
* Este artículo forma parte de los proyectos de investigación «Nobilitas II- Estudios y base documental de la nobleza del Reino de Murcia, siglos XV-XIX. Segunda fase: análisis comparativos», financiado por la Fundación Séneca, Agencia de Ciencia y Tecnología de la Región de Murcia (15300/PHC/10) y «Entornos sociales de cambio. Nuevas solidaridades y ruptura de jerarquías (siglos XVI-XX)», financiado por el Ministerio de Economía, Industria y Competitividad (HAR2017-84226-C6-1-P).

Este artículo fue realizado por el autor durante el periodo de aprovechamiento de una beca de formación posdoctoral en el Instituto de Ciências Sociais da Universidade de Lisboa concedida por la Fundación Séneca, Agencia de Ciencia y Tecnología de la Región de Murcia (19816/ $\mathrm{PD} / 15)$.

1 f.precioso@gmail.com / fpi13824@um.es /

ORCID iD: https://orcid.org/0000-0003-1136-5155
}

\section{INTRODUCCIÓN}

El siglo XVIII español conoció una etapa singular en la historia de su poderoso tribunal de la Inquisición. Posiblemente quien mejor definiera este periodo fue Egido López al referirse a esa "agonía extrañamente vigorosa» con la que caracterizó la actuación del Santo Oficio en esta centuria. ${ }^{2}$ En este sentido, sin dejar a un lado la persecución de determinados colectivos heréticos y conversos, ${ }^{3}$ la

2 Egido López 1984.

3 Es de sobra conocida la evolución de la actuación inquisitorial en el siglo XVIII, muy especialmente el rebrote de procesos contra conversos experimentado entre los años 1715 y 1733. A modo de orientación remitimos a la sucinta bibliografía que citamos a continuación para que el lector interesado pueda profundizar en la presencia siempre latente 
Inquisición asumió también un papel muy determinado en la lucha política doméstica. ${ }^{4}$ Más allá de puntuales desencuentros jurisdiccionales mantenidos con diversos consejos, audiencias y demás organismos de la monarquía, ${ }^{5}$ los inquisidores adquirieron a lo largo de este siglo un rol muy significativo en la pugna entre partidarios y detractores de las políticas regalistas puestas en marcha por los ministros del rey. El choque entre el poder real y el inquisitorial se dejó entrever en momentos de especial tensión como los definidos por la actuación de Macanaz, ${ }^{6}$ Olavide $^{7}$ o el propio Campomanes, ${ }^{8}$ tres hombres de gobierno que en diferentes coyunturas del dieciocho intentaron cercenar la aparente autonomía de un tribunal difícil de encajar en la pretendida configuración absolutista de la monarquía borbónica. ${ }^{9}$

El conflicto entre la Inquisición y el gobierno real tuvo hondas repercusiones que escaparon de la esfera netamente política. Entre otras dimensiones nos interesa destacar aquí las consecuencias que en el terreno de las letras siguieron a la actividad censora desplegada por el tribunal sobre aquellas publicaciones relacionadas con las regalías, en general, y con la propia Inquisición, en particular. ${ }^{10}$ Prueba de ello fue la causa contra fray Nicolás de Jesús Belando por su Historia Civil de España, publicada en cuatro tomos entre los años 1740 y $1744 .{ }^{11}$

La obra de Belando se proponía historiar el reinado de Felipe V desde sus inicios hasta el año 1733, un objetivo que sin embargo tenía poco que ver con las historias al uso que tras la guerra de Sucesión y el cambio dinástico se venían publicando. ${ }^{12}$ En esta obra encontramos algo más que la mera descripción de los hechos bélicos o diplomáticos de este periodo, hechos centrales, sí, pero conjugados con multitud de acontecimientos sociales, económicos, culturales y políticos considerados dignos de interés por el autor. El significado de la publicación resulta claro para historiadores como Fernández Albaladejo, quien ha comprehendido la Historia Civil en el contexto de la publicística de corte bor-

del problema converso en la Inquisición dieciochesca, vid. López Vela 2014: 343-345; Kamen 2005: 290-292; Alpert 2001: 173-199; Peñafiel Ramón 1992; Domínguez Ortiz 1991: 103-110; Lera García 1987; Blázquez Miguel 1986: 144-149; Martínez Millán 1984.

4 Escaparía a nuestros propósitos hacer una relación exhaustiva de la bibliografía disponible sobre la Inquisición en el siglo XVIII. A modo de referencia citamos los importantes trabajos de conjunto en los que el lector interesado puede obtener una imagen bastante completa de la vida del tribunal en el llamado siglo ilustrado, vid. Domergue 1996; Herr 1990; Álvarez de Morales 1982; Bennasar 1989: 333-334.

5 López Vela 1988, 2014: 312-314; Martínez Millán 1983.

6 Precioso Izquierdo 2017: 201-232; Martín Gaite 1982.

7 Defourneaux 1959; Gómez Urdáñez 2002.

8 Vallejo García-Hevia 1994.

9 No es de extrañar que algunos de los proyectos de reforma del tribunal más importantes del siglo XVIII, como por ejemplo el impulsado por el propio Melchor Macanaz en 1714, coincidiera con la primera gran oleada de reformas administrativas del reinado de Felipe $\mathrm{V}$, vid. Dedieu 2000; Bernardo Ares 2004.

10 Muñoz Sempere 2003: 27-28; Zavala 1978: 367-375.

11 Historia Civil de España. Sucesos de la guerra y tratados de paz, desde el año de mil setecientos hasta e de mil setecientos treinta y tres. Madrid.

12 Sobre las corrientes ideológicas de la historiografía española de este periodo, vid. Villacañas Berlanga 2013; Coxe 1846-1847 [Reedición de la Universidad de Alicante, 2011, con estudio introductorio a cargo de Enrique Martínez Ruiz: 33-68]; Iñurritegui Rodríguez 2002; García Cárcel 2002; Stiffoni 1989. bonista impulsada por Felipe $\mathrm{V}$ a lo largo de su reinado. ${ }^{13}$ Sin entrar en contradicción con lo anterior, García Cárcel ha insistido en el componente más polémico de la obra, la defensa de las regalías, así como en la proximidad ideológica del autor con posiciones políticas favorables a la extensión de la jurisdicción real. ${ }^{14}$ Por su parte, Iris María Zavala ha destacado la apuesta de Belando por un tipo de narrativa diferente que se apartaba de lo descriptivo para dejar paso a una Historia propicia a la interpretación y a la reflexión crítica del lector, una opción que entre sus coetáneos más eruditos fue recibida con cierta suspicacia y alguna que otra crítica por lo que se consideraba falta de rigor en el método. ${ }^{15}$

A pesar de todo, el origen inmediato de sus problemas poco tuvo que ver con la crítica historiográfica de su tiempo. Tras haber publicado los tres primeros tomos con general aceptación de público, en 1744 terminaba de dar a la luz una cuarta parte en la que se repasaban algunos de los capítulos más polémicos de la maltrecha relación seguida entre las cortes de Madrid y Roma durante la negociación de un nuevo acuerdo intentado entre los años 1713-1715. ${ }^{16}$ Belando se hacía eco así de uno de los enfrentamientos políticos más graves del inicio del reinado, dedicando numerosas páginas a la pugna suscitada entre el regalista Consejo de Castilla dirigido por el fiscal Macanaz y el Consejo de Inquisición al mando del italiano Francesco del Giudice. ${ }^{17}$

La manifiesta identificación del autor con la actuación de Macanaz y los juicios contrarios al exorbitante poder temporal de los inquisidores terminaron con la Historia Civil denunciada ante la Inquisición a mediados de 1744. La reacción posterior del historiador y de su abogado al elevar un memorial al rey criticando la ilegalidad de su proceso, complicó todavía más un asunto que acabó con ambos recluidos en cárceles secretas del Santo Oficio a comienzos de 1745.

La causa de Belando fue objeto, a su vez, de un minucioso análisis por parte de Melchor Macanaz, responsable indirecto de la desgracia del religioso. Desterrado de España tras dejar su empleo de fiscal general del Consejo de Castilla en febrero de 1715 e iniciarse contra él uno de los procesos inquisitoriales más largos y penosos de todo el siglo XVIII, Macanaz tomaba la pluma para mostrar cierta solidaridad con el historiador que de alguna forma lo había reivindicado tras décadas de ostracismo y que como él caía fulminado por el mismo tribunal.

En este artículo pretendemos analizar la interpretación que mereció para Macanaz el suceso de Belando. Si solo unos meses antes don Melchor había dejado escrito un primer comentario especialmente duro contra el trabajo del alicantino, ${ }^{18}$ poco después, tras tener noticia de su denuncia y condena, el juicio del ex fiscal parecía tornar hacia una

\footnotetext{
13 Fernández Albaladejo 2002: 502-505.

14 García Cárcel 2011: 309-311, 2005.

15 Zavala 1978: 367-370.

16 Martín Marcos 2011: 193-222; Bernardo Ares 2013: 639-642.

17 Precioso Izquierdo 2017: 201-216; Egido López 1984.

18 La obra a que nos referimos lleva por título: Males, daños y perjuicios que han ocasionado a la España, a su Iglesia, y a su Rey los estrangeros que han tenido manejo en el Ministerio Español. Todo en las notas puestas a la Historia Civil de España que compuso el Rmo. P. Fr. Nicolás de Jesús Belando... Por Don Melchor Rafael de Macanaz. Hemos trabajado la copia conservada en la Biblioteca Nacional de España (BNE, en adelante), Manuscrito (Mss, en adelante), 18402.
} 
especie de defensa aprovechada para volver a denunciar los excesos del Santo Oficio, lo que convierte su escrito en un auténtico discurso político contra la autonomía de la Inquisición y en definitiva como una muestra más del haz de posibilidades de su reforma. ${ }^{19}$

NO SIENDO DABLE QUE HAYA HISTORIA QUE AGRADE A LOS QUE SE INTERESAN EN QUE SE OLVIDE LO SUCEDIDO. LA INQUISICIÓN Y EL PROCESO DEL PADRE BELANDO

En los primeros días del mes de marzo de 1739 nada hacía presagiar al historiador y religioso franciscano, fray Nicolás de Jesús Belando, la polémica que su obra sobre el reinado de Felipe $V$ iba a suscitar. En ese momento se dirigía confiado al Consejo de Castilla para solicitar las licencias de impresión y venta necesarias en la publicación de cualquier obra. ${ }^{20}$ Tras haber superado el filtro de la «censura del Consejo, de su Religión y del Ordinario Eclesiástico ${ }^{21}$ y contar con la favorable (aunque también crítica) revisión que efectuó por encargo del rey el consejero de Guerra, don Francisco Manuel de Herrera, ${ }^{22}$ Belando entregaba a sus impresores los primeros volúmenes de la Historia Civil. El propio autor fue consciente del éxito casi inmediato que llegó a conocer su obra «en España, Italia y Francia, como se arguye de los muchos exemplares consumidos en tan breve tiempo y de la noticia que se tiene de estarse traduciendo para hacerla familiar a otras Naciones». ${ }^{23}$

La buena marcha de su trabajo se vio truncada a comienzos del mes de agosto de 1744 tras ser delatados «sus libros» a la Inquisición. Unos días después, al ser conocida la noticia, Belando se presentaba en Madrid para intentar aclarar el sentido de la denuncia y poder corregir aquello que se le señalara. De su encuentro con el inquisidor general apenas obtuvo respuesta más allá del compromiso un tanto amenazante- de que en «el caso de haber algo sería llamado", una premonición que anticipaba la serie de problemas con los que se encontró el autor a lo largo de las semanas siguientes. De hecho, tan temprano como el 6 de septiembre se publicaba un edicto contra su Historia Civil upor contener proposiciones temerarias, escandalosas, injuriosas y denigrativas de personas constituidas en alta Dignidad y depresivas de la autoridad y jurisdicción del Santo Oficio». ${ }^{24}$ Dos días antes de ese edicto, varios ministros de la Inquisición habían requisado del escritorio de Belando numerosos textos y documentos de trabajo. ${ }^{25}$

El inicio del proceso contra su obra obligó al autor a dejar nuevamente su convento valenciano de San Juan de Ribera y poner rumbo a Madrid. A mediados de septiembre de 1744 se entrevistaba otra vez con el inquisidor general y con el inquisidor de corte, unos encuentros de los que "salió con el desconsuelo de no haber podido entender de ninguna de las muchas preguntas hechas y respondidas en qué consistía el yerro cometido en su Historia para ocurrir

\footnotetext{
19 García Cárcel y Moreno Martínez 2002.

20 Archivo Histórico Nacional (en adelante, AHN), Consejos,

21 AHN. Inquisición, 4496/2, f. 1r.

22 Zavala 1978: 372-373.

23 Ídem.

24 AHN. Inquisición, 4496/2, f. $1 v$.

25 Ídem.
} 50635/21, s/n. al daño con su retractación». ${ }^{26}$ Ese error tenía seguramente que ver con el tratamiento dado por Belando a los sucesos que distanciaron las relaciones de Madrid y Roma durante la negociación de un nuevo acuerdo entre 1713 y 1715. Curiosamente su lectura de aquellos hechos se publicaba en la parte cuarta de su Historia Civil, apenas terminada. Lo que realmente parecía censurarse era la identificación del autor con las propuestas mantenidas entonces por el fiscal general del Consejo de Castilla, Melchor Macanaz, en su pugna con el Consejo de Inquisición liderado por Del Giudice e instrumentalizado por Alberoni. ${ }^{27}$

Desde luego, la acusación de parcialidad al autor y su obra era sobradamente merecida. A través de las páginas dedicadas por Belando a los hechos de ese periodo se recuperaba la controvertida memoria de uno de los políticos más polémicos de los inicios del reinado de Felipe $\mathrm{V}$, Melchor Macanaz, a quien al parecer había conocido el autor durante un reciente viaje a París. ${ }^{28}$ Impreso en la Historia Civil, Macanaz regresaba a la palestra de la opinión pública española y europea de 1740 para ser defendido -o al menos no atacado- por un historiador que por vez primera se hacía eco de sus reivindicaciones. Ejemplo de la positiva lectura de la circunstancia de don Melchor lo encontramos en la narración de la condena inquisitorial de la que fue objeto el Pedimento Fiscal de los cincuenta y cinco párrafos, memorial confeccionado por Macanaz a finales de $1713 .{ }^{29}$ La trama descrita por Belando podría pasar perfectamente por la pluma del mismísimo Macanaz, pues en ella se recogían muchas de las denuncias comunicadas por el ex fiscal en su asidua correspondencia y en los diversos escritos elaborados en los años de exilio en Francia y los Países Bajos (1715-1748). ${ }^{30}$ La acusación principal de Belando recaía sobre Del Giudice, el inquisidor general que con el beneplácito de Roma se había atrevido a condenar un documento de debate interno del Consejo de Castilla:

Por último se resolvió que se condenase pero que no se hiciese pública la condenación porque sabiéndola los españoles renovarían la memoria de los sucesos pasados entre ambas cortes sobre las censuras y prohibiciones promulgadas contra las obras de Don Francisco Salgado, Don Juan de Solórzano, Don Pedro Salcedo [...] Se tomó otro camino y fue enviar al Cardenal Judice un Breve por el qual se condenaban las obras de Guillermo y Juan Barclay, el libro de Mr. Talon y el papel referido Respuesta Fiscal, para que Su Eminencia, como Inquisidor General, hiciera pública la prohibición en la forma regular [...]. Del Giudice se aseguró la protección de Roma, añadiendo que lo haría mientras tuviese la protección de Su Santidad y de la Corte de Viena, para lo que pudiera resultar. ${ }^{31}$

Macanaz veía publicada al fin una interpretación de aquellos hechos próxima a sus intereses. Apartándose de la versión más favorable al Santo Oficio que podemos

26 AHN. Inquisición, 4496/2, f. 1v-2r.

27 Notas sobre la trayectoria política de Alberoni, vid. Barrio Gozalo 2011.

28 Zavala 1978: 371.

29 Un análisis del contenido del Pedimento Fiscal y las reacciones políticas que siguieron a su filtración, vid. Hernández Franco y Precioso Izquierdo.

30 Precioso Izquierdo 2017: 233-264.

31 Belando 1744, tomo IV: 62. 
encontrar en algunos historiadores como Bacallar, ${ }^{32}$ Belando optaba por recuperar la dimensión regalista de Macanaz para plantear al lector los límites de un enfrentamiento abierto entre los ministros encargados de defender la jurisdicción real frente a la mayoría de inquisidores celosos de las prerrogativas de la Iglesia y de los eclesiásticos en materia temporal. La estratagema de la condena del Pedimento Fiscal a cargo del inquisidor Del Giudice era - por sí solauna muestra más de aquella lucha entre los partidarios de una y otra política:

La determinación del Cardenal Giudice, el cual en el Palacio de Marli en Francia [...] firmó en el día 30 de julio del año de 1714 un Decreto con el qual y como Inquisidor General de España mandaba recoger y prohibir in totum [los libros de Barclay y Talon y el escrito fiscal]. Este Edicto lo remitió a Madrid el Inquisidor General para que se publicara y cuatro consejeros de Inquisición sin más reparo [...] lo firmaron y publicaron en las Iglesias a tiempo de Misa Mayor el día 15 de agosto. Luego corrió la noticia por la Corte y todos quedaban absortos. ${ }^{33}$

Quien tampoco se libraba de la diatriba del historiador era el entonces abate y futuro cardenal, Julio Alberoni, a quien acusaba de conspirar contra el fiscal convenciendo a la nueva esposa de Felipe V, la reina Isabel de Farnesio, de la conveniencia de la salida de la corte de Macanaz y el regreso del inquisidor Del Giudice:

Con toda armonía se iban templando las cosas quando el Cardenal Judice fabricaba maravillas en el discurso oprimido de lo que le pasaba [...] valiéndose de la Reyna Viuda, de sus Amigos en la Corte y hasta de Julio Alberoni. De esta manera fue facilitado su deseo y Alberoni muy aplicado a conseguirlo ponía todos los medios. Y cuando la reina Isabel Farnese venía a España y había llegado a Pamplona hizo los mayores esfuerzos. Llegó casi al último vale, valiéndose del padre Bellati, jesuita, confesor de la nueva reina, y sin salir de Pamplona le enseñó el escrito del Fiscal General, diciendo que por este papel estaba el Cardenal detenido en Bayona [...]. También le añadió que persuadiera a su Magestad que no creyera a don Melchor Macanaz y que luego que viese al Rey le pidiera lo apartase de su persona [...]. Y por último Alberoni, como buen agente, logró igualmente con sus influencias que el rey permitiera que Del Jiudice entrara en sus reinos. ${ }^{34}$

La conclusión final de Belando no admitía dudas sobre lo ocurrido con Macanaz. Reproduciendo lo escrito por el propio Alberoni en sus Memorias, se refería así a la operación orquestada tras la caída del fiscal y el inicio de un proceso inquisitorial que tuvo mucho de maniobra política: «No era nuevo artificio el de atacar a alguno por su Religión aunque injustamente, siendo cosa fácil concitar por este camino el

32 En sus Comentarios de la Guerra de Sucesión de España, Bacallar no ahorraba descalificaciones hacia don Melchor, a quien tachaba de "católico lisongero y ambicioso», "hombre nuevo en los Tribunales, poco jurisperito y envanecido», mientras que su Pedimento Fiscal le parecía elaborada en «términos temerarios, poco ajustados a la doctrina de los Santos Padres y que sonaba a herejía» así como «dispuesto a introducir en España el método de la iglesia galicana y una directa inobediencia a Concilio Tridentino», vid. Bacallar y Sanna 1727 [edición de 1957: 243259]; sobre la obra y trayectoria política de Bacallar, vid. Bogliolo 1989.

33 Belando 1744: 63.

34 Ibídem: 72. odio de una Nación que profesa tanta Religión y piedad».35 De esta forma, era cierto que la Historia Civil no escatimaba detalles sobre la conducta de los italianos Del Giudice y Alberoni, muy posiblemente las «personas constituidas en alta Dignidad" a las que se refería el edicto de septiembre de 1744. De la crítica al proceder de ambos se derivaba lo que por extensión podía considerarse como proposiciones «depresivas de la autoridad y jurisdicción del Santo Oficio».

Ante la imposibilidad de conocer los argumentos esgrimidos contra la Historia Civil, Belando decidió pasar al ataque y elaborar con la ayuda del abogado y religioso, José Antonio Quirós, ${ }^{36}$ un memorial en defensa fechado en 30 de diciembre de $1744 .{ }^{37}$ Para más inri el documento iba dirigido muy intencionadamente al rey como «Patrón del Santo Tribunal y de la protección de sus súbditos», ${ }^{38}$ una convicción que inspiraba el resto del escrito formado por un extenso «Capítulo único» en el que sobresalía una denuncia constante: no puede haber causa - escribían Quirós y Belando- «sin oír al reo». El requisito de la audiencia previa se hacía más necesario que nunca en este proceso: «En que no se puede probar el delito imputado sin convencer al reo, y en su defecto sin convencer a los Theologos que aprobaron sus libros». ${ }^{39} \mathrm{Y}$ es que para Belando la sola licencia concedida por los censores "para imprimir estos libros es como una sentencia a su favor y contraria a sus posibles opositores", una excusa que venía a sumarse a las demás razones que tanto para él como para Quirós invalidaban el proceso contra su Historia Civil, entre otras, el hecho de ser el autor

un Theologo Católico que habita en el Pueblo del Tribunal [...], haberse aprobado estos libros en el mismo Pueblo en que se trató de prohibirlos» y «no haberse delatado por contener proposiciones de inmediata oposición a verdades católicas [...] sino por haberse creído que son temerarias, escandalosas, erróneas, heresi próximas, que son voces con que se explican los grados de la oposición mediata. ${ }^{40}$

Lo que tampoco estaba dispuesto a admitir Belando era que su obra contuviese proposiciones «injuriosas y denigrativas de personas constituidas en alta Dignidad», ya que muy al contrario, era «referir delitos de tales personas acto equívoco a virtud [...] porque si son falsos los delitos, su Relator se sujeta a las penas impuestas a los que divulgan libelos famosos. Si verdaderos [...] acreditan por ello grandísima alabanza y condigno premio». ${ }^{41}$ De igual forma objetaba la acusación de que su Historia Civil incurriese en «proposiciones depresivas de la autoridad y jurisdicción del Santo Oficio», argumentando que él solo había escrito de los conflictos mantenidos por inquisidores con el rey y que la sola relación de «haber SM removido Ministros de su Real Consejo de la Suprema

\footnotetext{
35 Ibídem: 106. haber sido oído.

38 AHN. Inquisición, 4496/2, f. 2 r.

39 Ibídem: $3 r$.

40 Ibídem: $3 r-3 v$

41 Ibídem: 4v.
}

36 Sobre Quirós, un viejo austracista exiliado a Viena y vuelto a la España de Felipe V, vid. Mestre Sanchís 2003: 126-128.

37 El título completo es el siguiente: Queja dada al Rey por Fr. Nicolás de Jesús Belando de la Descalcez Franciscana, en recurso que, coadyuvado de su seráfica Religión, hace a la Real Persona de SM sintiéndose agraviado de la prohibición de sus Libros, determinada, sin 
[no] vulnera autoridad alguna del Santo Oficio». ${ }^{42}$ Belando se refería en concreto a dos procesos, el seguido contra el confesor de Carlos II, fray Froilán Díaz, ${ }^{43}$ y el más polémico todavía de Melchor Macanaz, cuya causa - se defendía el autor - «se lee muy diminuta en esta Historia, estando más extendida en otras que leí en Roma y en Viena». ${ }^{44}$

Posiblemente lo que contribuyó más a levantar el beligerante ánimo de la Inquisición contra la defensa de Quirós fue la permanente alusión al rey como freno y corrector último de los excesos inquisitoriales. Tal y como se podía leer en el documento era una apelación sobre la que se mostraban especialmente convencidos: «Aquí todos los súbditos de qualquier estado usamos de un derecho incontroverso de recurrir al Príncipe, implorando su protección contra la fuerza que hicieren qualesquier Jueces eclesiásticos, siendo el impartirla la Suprema Regalía, por ser su uso el que constituyó al Rey en ser tal; y negarse a él, se tiene por acto equivalente al de renunciar la Corona». ${ }^{45}$ La competencia real era más necesaria y oportuna que nunca al tratarse en esta ocasión de una obra sobre las regalías «lo que toca única y privativamente el conocimiento y decisión de la duda que sobre ello hubiere al Rey y a su Consejo de Castilla». ${ }^{46}$

El escrito de defensa concluía con el recuerdo - a medio camino entre la denuncia y la queja- de lo sucedido con Macanaz, a quien parecía tomarse como precedente nada halagüeño del caso. Belando establecía cierto paralelismo entre lo que consideraba un pronunciamiento favorable del rey a través de las licencias otorgadas para la publicación de su obra y el que en 1714 había dispensado a Macanaz contra el inquisidor general Del Giudice. Nada aseguraba entonces al propio autor un final diferente al de don Melchor: "Vemos un Fiscal desterrado, delatado de Hereje y secuestrados sus bienes, sin que en 30 años haya habido quien se interese en la prosecución de su causa ${ }^{47}$ Con el fin de evitar problemas semejantes recurría al monarca con la esperanza de que a través de su intervención se le señalara qué era lo que realmente se censuraba de su obra, solicitando a Felipe V que ordenara «que su Real Consejo de la Suprema [...] le mande dar traslado de la delación y calificaciones, sin los nombres del Delator y Calificador, y que opuestas todas las defensas, se vea con todos los Ministros que componen dicho Real Consejo a reserva de aquellos que tuvieren amistad o dependencia con dichos Delator o Calificadores $" .^{48}$ Esta última frase nos pone sobre aviso de las sospechas que el propio Belando tenía acerca de quién o quiénes podían estar detrás de la denuncia de su Historia, conjeturas que parecían confirmarse en un borrador de una carta dirigida por el autor - muy posiblemente- al marqués de Villarías, secretario del Despacho a finales del reinado de Felipe $V$, en la que tras solicitar su ayuda se apuntaba de manera indirecta a la responsabilidad de los jesuitas: ${ }^{49}$ "que por nuevos

\footnotetext{
42 Ibídem: $5 v$.

43 Sobre el proceso inquisitorial seguido contra el confesor real Froilán Díaz, vid. Martínez Peñas 2007: 522-527; Gómez Roán 2006; García Barriuso 1984; Kamen 2005a: 503-504.

44 AHN. Inquisición, 4496/2, f. 6 r.

45 Ibídem: 8r.

46 Ibídem: $8 \mathrm{v}$.

47 Ídem.

48 Ídem.

49 Quien no tuvo dudas sobre la responsabilidad de los jesuitas y muy en concreto del confesor de Felipe V, el padre Févre, fue Gregorio
}

Calificadores, no solo Theologos sino también Civiles, y sin que intervenga alguno de la Religión de la Compañía, se vea sin pasión y con justicia la mencionada Historia Civil de España para expurgar lo que fuera digno de censura»..$^{50}$

La reacción del Santo Oficio ante la divulgación de la defensa escrita por Quirós y Belando no se hizo esperar. A mediados de enero de 1745 el fiscal de la Inquisición de corte mandaba hacer presos en cárceles secretas del tribunal al historiador y a su abogado, a quienes tachaba de «delinquentes temerarios» por haber "escrito y dado a la prensa y aun repartido un mal papel o memorial con muchas proposiciones respectivamente escandalosas, abusivas de la Sagrada Escritura, inobedientes a los preceptos eclesiásticos y gravísimamente injuriosas al Sto. Oficio». ${ }^{51}$ Según consta en las alegaciones fiscales de Belando, su prisión fue practicada el 2 de febrero en un convento madrileño de su misma Orden..$^{52}$ En el momento de la detención lo acompañaba un fraile franciscano, fray Pascual Jover, hermano del consejero de Castilla, Blas Jover Alcázar..$^{53}$ Misma suerte corrió su abogado, quien antes de ser hecho preso por el Santo Oficio intentó una estrafalaria huida ayudado por un criado "que hizo de espaldas a su amo para que escapara». ${ }^{54}$ En sus declaraciones posteriores ante los inquisidores, Quirós insistía en su convencimiento de haber obrado correctamente al redactar y firmar la defensa de Belando, pues lo hizo con el único fin «de servir a Dios y solicitar poner corriente la Historia Civil pareciéndole que en ella no había proposiciones heréticas $" .{ }^{55}$ Lo más interesante de las respuestas de Quirós lo encontramos en la confesión de algo que parecía un secreto a voces: la más que probable intervención de Macanaz -o de alguien cercano- en la redacción de la defensa. El propio reo declaraba a los inquisidores el ofrecimiento por parte de un pariente de don Melchor: «De algunos papeles de lo que con él sucedió, buscando medio de quitar la nota que podía seguirse a toda su parentela por el Edicto y proceso causado en el Santo Oficio contra D. Melchor de Macanaz». ${ }^{56}$ Sin embargo, el mismo abogado se apresuraba a negar cualquier negocio en esa dirección argumentando que no era su intención convertirse en su defensor «porque no es su pariente ni jamás ha tenido correspondencia con él» y que en todo caso le parecía bien que "siendo hereje [...] se supiese su error». ${ }^{57}$

Parece claro que uno de los motivos fundamentales de la denuncia de la Historia Civil fue la narración de los hechos acaecidos con Macanaz, anatemizado político por excelencia todavía en la España de 1740. La Inquisición no podía tolerar semejante reivindicación de quien había sido el enemigo a batir en 1715 , víctima y a la vez símbolo de los límites permitidos en la reforma de la monarquía por la que fue forzado a un prolongado destierro de España que duraba ya tres décadas. Por eso se tenía que actuar y se actuó contra Belando, quien

Mayans, quien intentó interceder a favor de José Antonio Quirós a raíz de su procesamiento inquisitorial, vid. Mestre Sanchís 2003: 127.

50 AHN. Inquisición, 4496/2, s/f, s/n.

51 AHN. Inquisición, 4496/2, s/f, s/n.

52 AHN. Inquisición, 3732/10, f. 3r.

53 Sobre la trayectoria de Jover Alcázar, vid. Molas i Ribalta 1995a: 300-301, 1995b; Fayard 1982: 353 y 418

54 AHN. Inquisición, 3732/5, f. 5 r.

55 Ibídem: 1v.

56 Idem.

57 AHN. Inquisición, 3732/5, f. 3r. 
en marzo de 1745 fue condenado a seis meses de destierro de Valencia y dos años de Madrid. La Historia Civil y la queja dada por Quirós fueron incluidas a su vez en las sucesivas reediciones del Índice de Libros Prohibidos. ${ }^{58}$

\section{EXCESOS, CRÍTICA Y REFORMA. LA INQUISICIÓN POSIBLE EN LA ESPAÑA DE LAS REGALÍAS.}

Las noticias sobre la censura de la Historia Civil y el proceso seguido contra Belando llegaron con cierta puntualidad a Melchor Macanaz. Posiblemente en París le serían comunicadas de forma confidencial por algún español que poblaba la corte de Luis XV o a través de la correspondencia que - mal que bien-continuaba manteniendo con buena parte de su familia y amigos en España. El efecto que hubo de causar en don Melchor quedó ampliamente recogido en un comentario escrito por él mismo bajo el título «defensa de la Historia que escribió Fr. Nicolás de Belando, y con este motivo, se explica como el Rey es el único árbitro absoluto del consejo y tribunales de Inquisición, como de los demás consejos y tribunales». ${ }^{59}$ Este comentario es posterior a los ya citados "Males, daños y perjuicios que han ocasionado a la España, a su Iglesia y a su Rey los extranjeros que han tenido manejo en el Ministerio Español...», trabajo que Macanaz finalizó en octubre de 1744 y en el que llevaba a cabo una revisión muy crítica del contenido de la obra de Belando. Gracias al exhaustivo análisis de Alabrús Iglesias conocemos con detalle la opinión que mereció para Macanaz la Historia Civil, enjuiciada en algunos puntos con severidad por sus numerosas omisiones y corregida en temas tan variados como las reformas de la administración central de la monarquía, las relaciones de Felipe V con la Santa Sede o la política exterior seguida por España desde $1714 . .^{60}$

En este sentido, la «defensa de la Historia» tuvo que ser escrita necesariamente después del proceso y condena de Belando, entre otras razones, porque el propio Macanaz incorporaba en la parte inicial la queja escrita por Quirós. Las referencias a la pena impuesta al autor así como las permanentes alusiones a Felipe $\mathrm{V}$, hacen presuponer en cualquier caso una fecha posterior a marzo de 1745 y anterior a julio de 1746, periodo en el que Macanaz sobrevive en París alejado de los grandes cenáculos políticos franceses y casi olvidado por la corte española. ${ }^{61}$ Lejos del rigorismo mostrado en "Males, daños y perjuicios...», Macanaz dejaba entrever en esta ocasión cierta solidaridad con el historiador

58 Todavía se podía ver incluido a principios de siglo XIX en el Índice general de los libros prohibidos: compuesto del índice último de los Libros prohibidos y mandados expurgar hasta fin de diciembre de 1789 por el Señor Inquisidor General y señores del Supremo Consejo de la Santa General Inquisición, de los suplementos del mismo, que alcanzan hasta 25 de agosto de 1805 y ademas de un Index librorum prohibitorum juxta exemplar romanum jussu SS. D. N. editum anno MDCCCXXXV, en el que van intercalados en sus respectivos lugares los prohibidos hasta fin de 1842, p. 181.

59 El subtítulo tampoco dejaba lugar a dudas: «Los escándalos que malos inquisidores han dado, cómo han sido castigados y la necesidad que hay de desterrar de un tan Santo Tribunal los abusos que malos Ministros han introducido». Según una nota en una de las páginas finales, el manuscrito que nosotros hemos utilizado es una copia del original: «En 9 de septiembre principié esta copia, y la concluí en veinte y cinco de él», BNE, Mss. 8921, f. 52r.

60 Alabrús Iglesias 2005-2006.

61 Precioso Izquierdo 2017: 255-264. que trató de recuperar su memoria vindicada. Aunque le siguieran pareciendo insuficientes las críticas explícitas -e implícitas - de Belando al tribunal, todo ello se vuelve secundario y cede ante la denuncia del nuevo abuso cometido por la Inquisición contra una obra y un autor al que:

Solo se le persiguió y persigue por haber hablado algo del mucho mal que hizo cierto Ministro extranjero [...]. Del mismo papel prohibido se ve claro que Belando y Quirós por no atreverse a decir claro que la Inquisición mantiene hoy dia el ateísmo puro con capa de religión que inventó el inquisidor general [Baltasar de] Mendoza [y Sandoval] y después renovaron y dejaron sentado en ella los cardenales Judice y Alberoni [...] para apartar del lado del Rey a sus fieles Ministros. ${ }^{62}$

La sintonía con las reivindicaciones en clave regalista de Belando era total. Haciendo suyas las denuncias del autor, Macanaz volvía a la carga para subrayar lo que consideraba una nueva intromisión de la Inquisición en un tema bien ajeno a sus intereses, recordando que la obra censurada:

No había tratado de otra materia que de los hechos notorios que habían ocurrido en el reinado del mismo rey Felipe V, y que aquel Monarca había ordenado, visto y aprobado, sin entrar directa ni indirectamente en materias que fuesen la menor cosa opuestas a nuestra Santa Fe Católica y buenas costumbres, que quando alguno la hubiese de prohibir en España había de ser el Rey o su Consejo de Castilla. ${ }^{63}$

Para el ex fiscal, los inquisidores habían actuado de espaldas al rey, sin dar cuenta al monarca del proceso contra Belando y la prohibición de su obra, ya que de lo contrario Felipe $\mathrm{V}$ no lo habría permitido y se habría resuelto a actuar contra ellos tal y como en su día hizo contra «el Inquisidor General Mendoza y el Fiscal de aquel Consejo dn. Juan Fernández de Frías, porque le pretendieron cortar su autoridad privativa en todo lo tocante a la Inquisición», o el caso más flagrante del cardenal Del Giuduce, a quien «privó por dos veces del empleo de Inquisidor General, y a otros ministros de aquel Consejo que por mucho menos había echado de sus reynos». ${ }^{64}$ Este modo de proceder era consecuencia directa del gran problema detectado por Macanaz en su comentario, es decir, la insólita autonomía con la que actuaban los miembros del tribunal «como si no hubiese Dios, Rey ni otro alguno en este Mundo ni en el otro a quien sus Ministros hubiesen de dar cuenta ni de quien dependiesen $»{ }^{65}$ Ese margen de autonomía incomprensible para Macanaz resultaba perfectamente rastreable en multitud de expedientes que como el suyo, el de fray Froilán Díaz o ahora el de Belando y su Historia Civil demostraban una dolorosa evidencia: «Que la Inquisición se emancipaba» sin que ni siquiera el propio Felipe $\mathrm{V}$, a pesar de sus repetidos pronunciamientos contra los «malos inquisidores», pudiera evitarlo. ${ }^{66}$

De ahí que rápidamente hiciera lo que siempre que tenía oportunidad hacía en cualquiera de sus escritos, esto es, recurrir a su propio caso como ejemplo de todo aquello que

62 BNE, Mss. 8921, ff. 53r-59r.

63 Ibídem: $55 \mathrm{r}$.

64 Ibídem: $56 \mathrm{v}$

65 Ibídem: 144r.

66 Ibídem: 68v. 
pretendía argumentar. Que la Inquisición se extralimitaba de sus funciones primeras de control y pureza de la religión lo demostraban las luchas y forcejeos con Del Giudice a cuenta de la censura de su Pedimento Fiscal; ${ }^{67}$ que la Inquisición no acataba las órdenes del rey lo evidenciaba la resistencia de los inquisidores a aceptar los nombramientos de nuevos consejeros de la Suprema intentados por él mismo a finales de $1714 ;^{68}$ que la arbitrariedad era norma común en la mayoría de los procesos seguidos contra los defensores de la jurisdicción real lo reflejaba bien su peregrinar fuera de España o la injusta causa de su hermano fray Antonio. ${ }^{69}$ Esta personalización del discurso servía a Macanaz como patrón de muestra para reiterar la más que criticable autonomía del tribunal, un hecho que iba de la mano del otro gran vicio señalado por don Melchor en su comentario y que tenía que ver con la intromisión de la jurisdicción inquisitorial en casi cualquier asunto:

Desde la muerte del rey Felipe II acá en todos los Dominios de VM los malos Inquisidores no hay especie de negocio, por más ajeno que sea de su Ministerio, instituto y facultades, en que con qualquier flaco motivo no se abroguen el conocimiento. No hay vasallo por más independiente de su potestad que no le traten como a súbdito el más inmediato, subordinándole a sus mandatos, censuras, multas, cárceles, y lo que es más, a la nota de estas execuciones. ${ }^{70}$

El problema que se planteaba era de estricta competencia, subrayándose así la denuncia de la relativa independencia con la que actuaban los inquisidores como si no se viesen comprometidos por lo dispuesto por el rey o sus ministros. Pero ¿quiénes eran esos «malos inquisidores»? El propio Macanaz los definía como «aquellos que han puesto a los Reyes en la necesidad de deponerlos de sus empleos», ${ }^{71}$ una respuesta que le permitía volver a cargar las tintas contra su gran enemigo, el inquisidor Del Giudice. ${ }^{72}$ Por su actitud y poca prudencia, el proceder de esos «malos inquisidores» no podía tener otro resultado que el debilitamiento de la jurisdicción y las regalías de la Corona:

En la forma de sus procedimientos y en el estilo de sus despachos, usan y afectan modos con que deprimir la estimación de los Jueces Reales ordinarios y aun la autoridad de los Magistrados superiores, y esto, no solo en las materias judiciales y contenciosas, pero en los puntos de Gobernación política y económica ostentan esta independencia y desconocen la soberanía. ${ }^{73}$

Por eso los «tiros» de don Melchor se dirigían muy especialmente a la deriva de una institución capaz de sortear el parecer del rey o su gobierno. En ningún momento encontramos en Macanaz debates más profundos sobre la oportunidad de la Inquisición o el cuestionamiento de su función básica de lucha contra la herejía, una de las obligaciones más preclaras -entendía el autor - de la soberanía de todo

67 Ibidem: $72 r-77 r$.

68 Ibídem: 97-104

69 Ibídem: 114r-115v. Sobre el proceso inquisitorial seguido contra fray Antonio Macanaz, vid. Precioso Izquierdo 2014.

70 BNE, Mss. 8921, f. 129r.

71 Ibídem: 123 .

72 Ibídem: $108 \mathrm{v}-109 \mathrm{r}$.

73 Ibídem: 129v-130r. monarca católico. ${ }^{74}$ Lo que se criticaba abiertamente era la evolución seguida por el tribunal:

Desde que los Reyes Católicos hicieron de solo este miembro un Juzgado aparte, que es el que ha degenerado así como Judas y tantos otros monstruos como él degeneraron desde que hubo un Caín; y así a los que atacamos son a los Inquisidores que han seguido $y$ siguen monstruos tales como Caín y Judas, no a los que han sabido cumplir con el orden de Dios siguiendo las Santas Leyes que para ello les han dado los Reyes. ${ }^{75}$

Si el miedo o el engaño podían explicar inicialmente la ausencia de una respuesta firme por parte del rey, la causa última de semejante orden de cosas había que buscarla en un nivel todavía más degradado de la política, en concreto, en la lacerante alianza entre los «malos inquisidores» y los «malos gobernantes»:

Si se mantienen sin el merecido castigo las tiranías y sacrílegos atentados con que en todo han obrado y obran, es porque les dan la mano a todo ello los mismos que han tenido y tienen tiranizado el mando del universal Gobierno, tratándolos en esto como fieles Ministros de sus tiranías, reconociendo ellos mismos que sin tales pies, las cabezas de tales tiranos se venían por tierra, y al contrario, cuantos Inquisidores ha habido y hay hoy día, sin el apoyo de tales tiranos, se hacían y eran dignos de un severo castigo. ${ }^{76}$

El problema del abuso del fuero inquisitorial y la extralimitación de los inquisidores encontraba para Macanaz una coartada en los ministros y gobernantes que preferían mirar para otro lado o bien aprovechar tal degeneración en beneficio propio, una práctica que en su caso achacaba a Alberoni y más tarde a Patiño. ${ }^{77}$ Fuera una u otra razón, el resultado no podía ser más lesivo para la jurisdicción del rey, vetada en la regulación del Santo Oficio, ya que "los inquisidores con no hacer más que lo que les mandan los del gobierno tiránico, publican en voz y por escrito y le dicen al Rey mismo en sus consultas, representaciones y respuestas que todo el Ministerio de la Inquisición [...] está a su cuidado por Ministerio Apostólico y derecho eclesiástico, que por esto les toca a ellos privativamente ${ }^{78}{ }^{78}$ Frente a la alianza de los inquisidores y el mal gobierno poco o nada podían hacer los defensores de las regalías, pues como se había comprobado en el expediente de Belando y Quirós, eran capaces de formar contra ellos: «Herejías nuevas, prohibiendo como heréticas las verdades católicas y secuestrando los bienes a los que las escribieron [...], el último ejemplar del célebre abogado don José Antonio de Quirós ha llenado de horror a la República Literaria y a todo hombre de honor». ${ }^{79}$

74 Esta es una de las claves más significativas del pensamiento político del autor. A mediados de la década de 1730 publicó una obra en defensa del Santo Oficio en la que se dedicaba a rebatir punto por punto las principales acusaciones vertidas contra la Inquisición por parte de escritores «herejes y católicos vagamente convencidos». Acerca del papel y la función reconocida por Macanaz a la Inquisición, vid. Precioso Izquierdo 2016

75 Ibídem: 212v.

76 Ibídem: 207r.

77 Idea planteada ya en el primer comentario a la obra de Belando, vid. Alabrús Iglesias, R. Mạ. 2005-2006: 192-201.

78 BNE, Mss. 8921, f. 204v.

79 BNE, Mss. 8921, f. 194r. 
Esta afirmación final sirve para introducirnos en la última denuncia formulada por Macanaz en su escrito, la relativa a la interferencia de la censura inquisitorial en cualquier publicación por más ajena que fuera a su competencia:

Si se hiciese reconocer el Índice de Libros prohibidos que hizo imprimir el Rey don Felipe Segundo y compararlo con el que ahora tienen, hallaría SM que en aquel no se prohibió otra cosa que los libros y escritos dogmatizantes, y que en el que ahora tienen, se ven condenados todos los que mantienen la disciplina Apostólica que ilustraron los Primeros Padres y Concilios de la Iglesia de España en su Código, con ser este el último seguro y cierto que tiene la Iglesia Universal para su gobierno [...], mientras dejan correr como de sana doctrina todos los que tratan de ilustrar la corruptela de la disciplina exterior de la Iglesia. ${ }^{80}$

La intromisión de la censura inquisitorial se hacía todavía más insoportable en aquellas obras de contenido político, ${ }^{81}$ un ámbito en el que - según Macanaz- no se hacía otra cosa que perseguir títulos que pudieran contener apologías de las regalías o alguna que otra crítica al poder de los inquisidores:

Ellos prohíben quanto se escribe por el gobierno público, político, económico, gubernativo, jurídico y contencioso que directa o indirectamente no sea conforme a sus máximas [...]. A la Política de Bobadilla, las obras de Quevedo e infinitas otras con el título de corregirlas las han borrado lo que es defensa de la Corona, o de enseñanza, o diversión, como se ha dicho que lo hicieron con los Bolandos, y se sabe que lo han hecho con los del eruditísimo Feijoo, el que de aburrido se ha visto forzado a dejar de continuarla, siendo infinitas más los que han suprimido o condenado en cosas ajenas de su Ministerio. ${ }^{82}$

Más que lamentar el perjuicio que podía suponer para las letras o la cultura, la queja de Macanaz denunciaba el daño sufrido por la jurisdicción real y las regalías ante el uso abusivo de las censuras inquisitoriales:

Pregúnteseles porqué han prohibido los tres tomos en folio de la Historia Civil de España de Belando, engañando al Mundo con el edicto que contra ellos se publicaron en septiembre de 1744 [...], mientras acá están en las librerías de varios cuerpos, y de los curiosos y aplicados, ningún hombre docto por más atención que ha puesto en leerlos les ha hallado, y otro alguno les hallará, nada de quanto contra ellos dicen, fuera de que todo lo que les imputan, toca, si así fuese, a corregirlo al Consejo de Castilla, y en este no se halló nada que corregir. ${ }^{83}$

Es interesante destacar cómo para Macanaz el problema de la censura de obras políticas no se entendía tanto en términos de extralimitación sino simplemente como una usurpación de funciones que solo competían al rey y a sus

80 Ibídem: $121 v-122$.

81 Sobre la censura inquisitorial en tiempos de Felipe V, vid. Peña Díaz 2014. La práctica censora de los inquisidores contra publicaciones «políticas» será continua durante el siglo XVIII hasta el ocaso de la institución, vid. Alejandre 2006; tampoco la prensa, aunque más tardíamente, se libró del interés censor de la Inquisición, vid. Larriba 2005.

82 BNE, Mss. 8921, f. 194r.

83 Ibídem: $125 \mathrm{r}-125 \mathrm{v}$. tribunales. Por eso se remontaba en la historia y buscaba precedentes ejemplares que demostraran la capacidad de reacción de los reyes ante las censuras y prohibiciones procedentes de Roma o de la Inquisición contra la literatura pro regalías, como se podía ver en la prohibición de Felipe III al tomo XI de los Annales Eclesiásticos del Cardenal Baronio, «por lo que en él escribió contra la regalía de la Monarquía de Sicilia», ${ }^{84}$ o como en su día hizo Felipe IV contra la publicación en España del Índice de Libros Prohibidos por contener las obras de «Salgado, Solórzano, Salcedo, Larrea, Fraso y otros escritos, todos ellos en defensa de las regalías de la Corona de España». ${ }^{85}$

Desde entonces, concluía Macanaz, tanto Roma como Madrid se habían cuidado y mucho de tener a punto sus respectivos aparatos censores para controlar la circulación de libros procedentes de uno y otro centro: «En Roma en prohibir los Libros españoles que se han escrito en defensa de las regalías de la corona, y la España lo ha puesto en retener las Bulas, Breves, rescriptos y aun el Índice Romano, en que se prohíben tales Libros y otros hechos en defensa de las regalías ${ }^{86}$

Así visto no cabía otra competencia que no fuera la del rey para controlar obras de contenido político y gubernativo, como tampoco cabía imaginar un monarca que no hiciera uso de la censura gubernativa contra las publicaciones que pusieran en duda sus regalías. ${ }^{87}$ De todo lo cual se infería, como no podía ser de otra manera en el caso de Macanaz, una presencia casi omnímoda del rey en el tribunal de la Inquisición, centralidad sobre la que hacía girar cualquier intento de reforma que debía pasar, sí o sí, por la sumisión total del Santo Oficio y de los inquisidores al rey y su jurisdicción. Por esta razón, casi medio siglo después, don Melchor consideraba oportuno recordar la Junta Magna de 1696 como paradigma o guía de la reforma necesaria. ${ }^{88}$

Los resultados de esa reunión - que Macanaz conocía perfectamente ya que habían servido para fundamentar en 1714 su intento de reforma del Santo Oficio ${ }^{89}$ - le seguían pareciendo válidos. Al menos en esencia, don Melchor estimaba que las conclusiones del memorial elevado a Carlos II por los miembros de la Junta podían ser útiles como marco general para llevar a cabo la adecuación de la Inquisición a un escenario político proyectado en términos absolutos a favor del rey. De ahí la memoria intencionada de las principales prohibiciones propuestas por la Junta, en especial, las tocantes a la reforma de los abusos y excesos cometidos por los inquisidores en el uso de una más que criticable jurisdicción temporal que proponía: «Quitar enteramente [...] pues Carlos V la tuvo diez años sin ella, y en ellos no dejó la Religión de mantenerse en su mayor pureza». ${ }^{90}$ Tampoco veía mal la limitación de las censuras inquisitoriales, ya que «el abuso que hacen los inquisidores en esto es tal que usan de las censuras aun en las cosas más mínimas y totalmente ajenas a

84 Ibídem: $170 v-171 r$.

85 Ibídem: $172 \mathrm{r}$.

86 Ibídem: $171 r$.

87 Sobre la censura gubernativa y las relaciones entre el gobierno y los inquisidores en el siglo XVIII, vid. Durán López 2016; Pampliega Pedreira 2013; Domínguez 2013; Caro López 2004; Bragado Lorenzo y Caro López 2004.

88 Martínez Millán 1985; López Vela 2014: 312-314.

89 Vallejo García-Hevia 1996; Egido López 1984: 1233-1240.

90 BNE, Mss. 8921, f. 132r. 
su ministerio.${ }^{91}$ Finalmente recomendaba eliminar el conocimiento de los recursos de fuerza concedido por Felipe II a la Inquisición, un exceso «que se hizo ver con multitud de exemplares en los reinados de Felipe III y IV y de Carlos II» y que solo había contribuido a «poner a los otros Consejos, Chancillerías y Audiencias en la indispensable necesidad de usar del remedio de la fuerza para contenerlos». ${ }^{92}$

Las prohibiciones recordadas por Macanaz en su discurso ponían el foco de la reforma en la competencia externa de la Inquisición, es decir, en todos aquellos medios que servían de excusa legal al Santo Oficio para extender su capacidad en asuntos bien lejanos a sus fines originales. A finales del reinado de Felipe $\mathrm{V}$, Macanaz volvía de nuevo la vista a sus propias fuentes de trabajo y fiaba -como en 1714la reforma de la Inquisición a una profunda reorganización por la que quedase definitivamente reducida a la dependencia del rey. Inquisición, sí, pero bajo estricta supervisión del monarca, condición sine qua non para una óptica tan marcadamente regalista como la del ex fiscal: "Que los Reyes de España han sido y son los únicos Legisladores de su Inquisición, que de ellos depende el todo de ella y en el Mundo no hay otro superior de quien dependa que del mismo Rey, a quien la Santa Sede y los Obispos tienen fiado en esto". ${ }^{93}$ Con un exilio a cuestas de más de tres décadas motivado por un latente y molesto proceso inquisitorial, se entiende la última reflexión de don Melchor dirigida contra todos los que desde 1714, fecha de su fracaso político, habían ocupado sus puestos tanto en el gobierno como en el tribunal: «Verdaderos ateístas, sin Dios, Rey, Ley ni otra Religión que la que su torpe ignorancia y ciega pasión les dicta según ven que les conviene para llevar adelante su tiránico, temerario y diabólico sistema de degradar al Rey, por no haberlo podido destronar $» .^{94}$

\section{CONCLUSIONES}

A pesar del título del comentario "en defensa» de la Historia Civil de España, el escrito de Macanaz tuvo bastante poco de resarcimiento de la obra de Belando y sí mucho de crítica a los excesos del tribunal. Dicho de otro modo, si hubo algo de defensa fue por la vía del ataque al proceder del Santo Oficio, con escasas alusiones al contenido de la Historia, juzgada muy despectivamente -como demostró Alabrús Iglesias - en un primer pronunciamiento. De lo que se trataba ahora no era de mudar el criterio sentado entonces sino de solidarizarse con el autor y su abogado contra lo que podía considerarse un nuevo episodio de injerencia inquisitorial en un ámbito extraño por completo a su labor.

Como hemos tenido oportunidad de comprobar, lo escrito por el ex fiscal venía a sumarse a lo intentado por él mismo en 1714 contra una Inquisición que - para algunos autores regalistas ${ }^{95}$ - no terminaba de encajar del todo

91 Ibídem: $133 r$.

92 Ibídem: 133v-134r.

93 Ibídem: 205v.

94 Ibídem: 209v-210r.

95 Como anotó hace años Álvarez de Morales, la tradición regalista continuó durante la segunda mitad del siglo XVIII elevando diversos proyectos de reforma del tribunal en este mismo sentido, es decir, dirigidos a la afirmación de los derechos del rey en el seno del Santo Oficio, vid. Álvarez de Morales 1977. en el entramado político de la España borbónica. Su objetivo no era acabar con el Santo Oficio ni poner en cuestión sus funciones de represión y lucha contra la herejía, tareas nunca objetadas por don Melchor. ${ }^{96}$ Lo que pretendía a través de la crítica al proceso de Belando era subrayar nuevamente los límites de lo tolerado para un tribunal que debía guardar obediencia ciega al rey. Su reforma y el recuerdo de las prohibiciones de la Junta Magna de 1696 iban precisamente en la dirección de asegurar una mayor presencia de la jurisdicción real en la Inquisición, reduciendo a la mínima expresión cualquier competencia temporal que pudiera justificar episodios como el suyo o el de Belando.

Con recurrentes ejemplos históricos, Macanaz trataba de demostrar el papel de "árbitro absoluto» del rey en el seno del tribunal, una realidad que chocaba con la cuestionable autonomía imputada a la institución y a sus miembros en perjuicio de la Corona. El indiscriminado y arbitrario uso de las censuras y su repercusión en el campo de la literatura jurídica y política evidenciaban la necesidad de poner coto a los desmanes de los inquisidores. En este punto, la crítica se ampliaba y dirigía sus miras hacia otro de los blancos preferidos del discurso de Macanaz, los "malos gobernantes», es decir, todos aquellos que desde su apresurada salida de la Corte no habían sido capaces - bien por interés propio o para evitar problemas mayores - de subvertir tal situación en favor del rey.

El proceso a la Historia Civil de España encontró en Macanaz una respuesta firme y contundente. Paradójicamente no se plasmó a favor de la lectura y el contenido de la obra de Belando, en tantos puntos rebatida detalladamente por el propio Macanaz. ${ }^{97}$ Su defensa lo fue principalmente de las regalías de la Corona en materia inquisitorial, un argumento presente en la Historia Civil y por el que don Melchor se decantaba. Repitiendo su discurso más regalista, Macanaz supo entender la oportunidad que le brindaron las noticias recibidas desde España para lanzar -otra vez - un órdago escrito en defensa de lo que posiblemente tanto Belando como él mismo entendían por "civil», esto es, la esfera de competencias propias o regalías pertenecientes al rey. La adecuación de la Inquisición a ese juego de poder presidido por el monarca pasaba únicamente por acatar su jurisdicción y quedar absolutamente bajo su control y dependencia. Este principio, planteado con total nitidez en las últimas décadas del siglo XVII, fue una constante en el imaginario político reformista de la segunda mitad del XVIII, un tiempo previo al estallido del gran debate teórico de finales de la centuria en el que ya no se excluirían otras alternativas incompatibles con la propia continuidad del tribunal.

\section{FUENTES}

Bacallar y Sanna, Vicente (Marqués de San Felipe). 1727. Comentarios a la Guerra de España e historia de su rey Felipe V, el Animoso [edición de C. Seco Serrano, Biblioteca de Autores Españoles, Madrid, 1957].

Belando, Nicolás de Jesús. Historia Civil de España. Sucesos de la guerra y tratados de paz, desde el año de mil setecientos hasta e de mil setecientos treinta y tres. Madrid.

\footnotetext{
96 Precioso Izquierdo 2017: 279-280.

97 Alabrús Iglesias 2005-2006.
} 
Índice general de los libros prohibidos: compuesto del Índice último de los Libros prohibidos y mandados expurgar hasta fin de diciembre de 1789 por el Señor Inquisidor General y señores del Supremo Consejo de la Santa General Inquisición, de los suplementos del mismo, que alcanzan hasta 25 de agosto de 1805 y ademas de un Index librorum prohibitorum juxta exemplar romanum jussu SS. D. N. editum anno MDCCCXXXV, en el que van intercalados en sus respectivos lugares los prohibidos hasta fin de 1842.

Macanaz, Melchor Rafael. Males, daños y perjuicios que han ocasionado a la España, a su Iglesia, y a su Rey los estrangeros que han tenido manejo en el Ministerio Español. Todo en las notas puestas a la Historia Civil de España que compuso el Rmo. P. Fr. Nicolás de Jesús Belando.

\section{BiBLIOGRAFÍA}

Alabrús Iglesias, Rosa María. 2005-2006. «El pensamiento político de Macanaz». Espacio, Tiempo y Forma, Serie IV 18-19: 177-201. https://doi.org/10.5944/etfiv.18-19.2005.3469

Alejandre, Juan Antonio. 2006. "La censura de libros y folletos de contenido político en las últimas décadas del siglo XVIII y en las primeras del siglo XIX». En Inquisición y censura. El acoso a la inteligencia en España, editado por Enrique Gacto Fernández, 89-150. Barcelona: Dykinson.

Alpert, Michael. 2001. Criptojudaismo e Inquisición en los siglos XVII y XVIII. Barcelona: Ariel.

Álvarez de Morales, Antonio. 1977. «La crítica al Tribunal de la Inquisición durante la segunda mitad del siglo XVIII». Estudis: Revista de historia moderna 6: 171-182.

Álvarez de Morales, Antonio. 1982. Inquisición e Ilustración (17001834). Madrid: FUE.

Barrio Gozalo, Maximiliano. 2011. «El Cardenal Alberoni y España. Política religiosa y carrera eclesiástica». Hispania Sacra LXIII, 127: 205-234. https://doi.org/10.3989/hs.2011.v63.i127.272

Bennasar, Bartolome (ed.) 1981. Inquisición española: Poder político y control social. Barcelona: Crítica.

Bernardo Ares, José Manuel de. 2004. «Felipe V: La transformación de un sistema de gobierno». En Felipe $V$ y su tiempo, editado por Eliseo Serrano Martín, vol. I, 967-990. Zaragoza: Instituto Fernando el Católico.

Bernardo Ares, José Manuel de. 2013. «La Iglesia entre Austrias y Borbones: la guerra de Sucesión y el pontificado de Clemente XI». En La Iglesia en la Historia de España, dirigido por José Antonio Escudero López, 627-643. Madrid: Marcial Pons.

Blázquez Miguel, Juan. 1986. El tribunal de la Inquisición de Murcia. Murcia: Real Academia Alfonso X El Sabio.

Bogliolo, Enrico. 1989. Tradizione e innovazione nel pensiero politico di Vincenzo Bacallar. Milán: Franco Angeli Libri.

Bragado Lorenzo, Javier y Ceferino Caro López. 2004. «La censura gubernativa en el siglo XVIII». Hispania: Revista española de historia LXIV, 217: 571-600. https://doi.org/10.3989/hispania.2004.v64.i217.188

Caro López, Ceferino. 2004. «Censura gubernativa, Iglesia e Inquisición en el siglo XVIII». Hispania Sacra LVI, 114: 479-511. https://doi. org/10.3989/hs.2004.v56.i114.132

Coxe, William. 1846-1847. España bajo el reinado de la Casa de Borbón (1700-1788). Madrid [Reedición de la Universidad de Alicante, 2011. Estudio introductorio a cargo de Enrique Martínez Ruiz].

Dedieu, Jean-Pierre. 2000. «La nueva planta en su contexto. Las reformas del aparato del Estado en el reinado de Felipe V». Manuscrits. Revista d'Història Moderna 18: 113-139.

Defourneaux, Marcelin. 1959. Pablo de Olavide ou I'afrancesado (1725-1803). Paris: PUF.

Domergue, Lucienne. 1996. La censure des livres en Espagne à la fin de l'Ancien Régime. Madrid: Casa de Velázquez.

Domínguez, Juan Pablo. 2013. «Reformismo cristiano y tolerancia en España a finales del siglo XVIII». Hispania Sacra LXV, Extra 2: 113172. https://doi.org/10.3989/hs.2013.038

Domínguez Ortiz, Antonio. 1991. Los judeoconversos en la España Moderna. Madrid: Fundación MAPFRE.
Durán López, Fernando (coord.). 2016. Instituciones censoras: nuevos acercamientos a la censura de libros en la España de la llustración. Madrid: CSIC.

Egido López, Teófanes. 1984. «La Inquisición en la España borbónica: el declive del Santo Oficio: la nueva coyuntura. La España del siglo XVIII». En Historia de la Inquisición en España y América, dirigido por Bartolomé Escandell Bonell y Joaquín Pérez Villanueva, tomo I, 1204-1210. Madrid: Biblioteca de Autores Cristianos.

Egido López, Teófanes. 1984. «Las reformas fracasadas. El significado de Macanaz». En Historia de la Inquisición en España y América, dirigido por Bartolomé Escandell Bonell y Joaquín Pérez Villanueva, tomo I, 1233-1240. Madrid: Biblioteca de Autores Cristianos.

Fayard, Janine. 1982. Los miembros del consejo de Castilla (16211746). Madrid: Siglo XXI.

Fernández Albaladejo, Pablo. 2002. «Dinastía y comunidad política: el momento de la patria». En Los Borbones. Dinastía y memoria de nación en la España del siglo XVIII, editado por Pablo Fernández Albaladejo, 485-532. Madrid: Marcial Pons-Casa de Velázquez.

García Barriuso, Patrocinio. 1984. «La crisis del Santo Oficio (16211700). Los acontecimientos en la Península: la época de Carlos II: el milagrismo, Sor Luisa de la Ascensión, la monja de Carrión, Fr. Froilán Díaz y el inquisidor Mendoza». En Historia de la Inquisición en España y América, dirigido por Bartolomé Escandell Bonell y Joaquín Pérez Villanueva, tomo I, 1089-1112. Madrid: Biblioteca de Autores Cristianos.

García Cárcel, Ricardo. 2002. «La opinión de los españoles sobre Felipe V después de la Guerra de Sucesión». Cuadernos de Historia Moderna. Anejos I: 103-125.

García Cárcel, Ricardo. 2005. «Los proyectos políticos sobre España en el siglo XVIII». En De Hispania a España. El nombre y el concepto a través de los siglos, editado por Vicente Palacio Atard, 237-251. Madrid: Temas de Hoy.

García Cárcel, Ricardo. 2011. La herencia del pasado. Las memorias históricas de España. Barcelona: Galaxia Gutenberg.

García Cárcel, Ricardo y Doris Moreno Martínez. 2002. «La Inquisición y el debate sobre la tolerancia en Europa en el siglo XVIII». Bulletin Hispanique 104 (1): 195-213. https://doi.org/10.3406/ hispa.2002.5108

Gómez Roán, Concepción. 2006. «La causa inquisitorial contra el confesor de Carlos II. Fray Froilán Díaz». Revista de la Inquisición 12: 323-389.

Gómez Urdáñez, José Luis. 2002. «El caso Olavide: el poder absoluto de Carlos III al descubierto». En Los grandes procesos de la historia de España, coordinado por Santiago Muñoz Machado, 308-334. Barcelona: Crítica.

Hernández Franco, Juan y Francisco Precioso Izquierdo. 2014. «Discursos enfrentados en los albores de la monarquía borbónica. Reacciones al Pedimento Fiscal de Macanaz». Mediterranea. Ricerche storiche XI/30 (Aprile): 63-84.

Herr, Richard. 1990. España y la revolución del siglo XVIII. Madrid: Aguilar.

Iñurritegui Rodríguez, José María. 2002. «Las Memorias del Conde de Robres: la nueva planta y la narrativa de la guerra civil». Espacio, Tiempo y Forma, Serie IV 15: 187-255. https://doi.org/10.5944/ etfiv.15.2002.3429

Kamen, Henry. 2005a [primera edición, 1981]. La España de Carlos II. Madrid: Critica.

Kamen, Henry. 2005b [primera edición de 1997]. La Inquisición española. Una revisión histórica. Barcelona: Crítica.

Larriba, Elisabel. 2005. «Inquisición y prensa periódica en la segunda mitad del siglo XVIII». Cuadernos de llustración y Romanticismo 13: 77-92. https://doi.org/10.25267/cuad_ilus_romant.2005.i13.04

Lera García, Rafael de. 1987. «La última gran persecución inquisitorial contra el criptojudaísmo: el tribunal de Cuenca (1718-1725)». Sefarad 47: 87-137.

López Vela, Roberto. 1988. "La inquisición a la llegada de Felipe V. EI proyecto de cambio en su organización y bases sociales». Revista Internacional de Sociología 1: 63-122

López Vela, Roberto. 2014. «Inquisición y cambio dinástico: la defensa de la constitución católica de la monarquía (1696-1715)». En 
Europa en torno a Utrecht, editado por Marina Torres Arce y Susana Truchuelo García, 311-352. Santander: Editorial de la Universidad de Cantabria.

Martín Gaite, Carmen. 1982 [primera edición, 1969]. Macanaz, otro paciente de la Inquisición. Barcelona: Destino Libro.

Martín Marcos, David. 2011. El papado y la Guerra de Sucesión española. Madrid: Marcial Pons.

Martínez Millán, José. 1983. "Crisis y decadencia de la Inquisición». Cuadernos de Investigación Histórica 7: 1-17.

Martínez Millán, José. 1984. «La persecución inquisitorial contra los criptojudíos en el siglo XVIII. El tribunal de Llerena (1700-1730)». En Historia de la Inquisición en España y América, dirigido por Bartolomé Escandell Bonell y Joaquín Pérez Villanueva, tomo III, 557-656. Madrid: Biblioteca de Autores Cristianos.

Martínez Millán, José. 1985. «Los problemas de jurisdicción del Santo Oficio: la Junta Magna (1696)». Hispania Sacra XXXVII, 75: 205-259.

Martínez Peñas, Leandro. 2007. El confesor del rey en el Antiguo Régimen. Madrid: Editorial Complutense.

Mestre Sanchís, Antonio. 2003. Apología y crítica de España en el siglo XVIII. Madrid: Marcial Pons.

Molas i Ribalta, Pere. 1995a. «Magistrados foráneos en la Valencia borbónica». Boletín de la Real Academia de la Historia 192 (2): 265-334.

Molas i Ribalta, Pere. 1995b. «Manteístas en Valencia, 1707-1759». Revista de Historia Moderna 13-14: 31-50.

Muñoz Sempere, Daniel. 2003. La Inquisición española como tema literario: política, historia y ficción en la crisis del Antiguo Régimen. Londres: Tamesis.

Pampliega Pedreira, Víctor. 2013. Las redes de la censura: el Consejo de Castilla y la censura libraría en el siglo XVIII. Tesis Doctoral. Universidad Complutense de Madrid.
Peña Díaz, Manuel. 2014. "Censuras bajo el reinado de Felipe V». En 1714. Cataluña en la España del siglo XVIII, editado por Antonio Morales Moya, 315-337. Madrid: Cátedra.

Peñafiel Ramón, Antonio. 1992. «Reductos judaizantes en el siglo XVIII. El Tribunal del Santo Oficio de Murcia». Revista de la Inquisición 2: 49-70.

Precioso Izquierdo, Francisco. 2014. «Tertulia y medios de circulación política en la España de Felipe V: fray Antonio Macanaz y el obispo Belluga (1714-1720)». Studia Historica. Historia Moderna 36: 327355. https://doi.org/10.14201/shhmo201436327355

Precioso Izquierdo, Francisco. 2016. «Una memoria controvertida. Melchor Macanaz y la Defensa Crítica de la Inquisición». Espacio Tiempo y Forma. Serie IV 29: 187-206. https://doi.org/10.5944/ etfiv.29.2016.15024

Precioso Izquierdo, Francisco. 2017. Melchor Macanaz. La derrota de un "héroe». Poder político y movilidad familiar en la España Moderna. Madrid: Cátedra.

Stiffoni, Giovanni. 1989. Verítá della storia e ragioni del potere nella Spagna del primo '700. Milán: Franco Angeli Libri.

Vallejo García-Hevia, José María. 1994. «Campomanes y la Inquisición: historia del intento frustrado de empapelamiento de otro fiscal de la Monarquía en el siglo XVIII». Revista de la Inquisición 3: 141-182.

Vallejo García-Hevia, José María. 1996. «Macanaz y su propuesta de reforma del Santo Oficio de 1714». Revista de la Inquisición 5: 187-292.

Villacañas Berlanga, José Luis. 2013. «Una idea y escritura de la historia en la conciencia nacional del siglo XVIII». Cuadernos Dieciochistas 14: 19-57.

Zavala, Iris M. 1978. Clandestinidad y libertinaje erudito en los albores del siglo XVIII. Barcelona: Ariel. 